\title{
Telemedicine uptake among Genetics Professionals in Europe: room for expansion
}

\author{
Ellen Otten ${ }^{\star, 1}$, Erwin Birnie ${ }^{1}$, Anneke M Lucassen ${ }^{1,2,3}$, Adelita V Ranchor ${ }^{4}$ and Irene M Van Langen ${ }^{\star 1}$
}

Today's economic challenges and the changing landscape of clinical genetics are forcing us to consider alternative ways of providing genetic services, to comply with budget limitations and at the same time meeting the demands of increasing patient numbers and patient-centered care delivery. Telegenetics could be an effective and efficient way of counseling, but its use in Europe is not widely reported, nor is there evidence of international collaboration. We conducted an online survey among 929 genetics professionals, to explore the current availability and use of different telegenetics modalities in Europe. Our questionnaire was completed by 104 clinically active European genetics professionals. Telephone genetic counseling was used by $17 \%$ of respondents. Videoconferencing facilities were available to $24 \%$, but only $9 \%$ of them used these for patient counseling. Various barriers to availability and use were cited, ranging from practical constraints, lack of professional support/ knowledge, to lack of perceived suitability and need. The results show that telegenetics modalities are not currently in widespread use by our respondents, in part due to perceived barriers. To meet the changing economic, genetic, and societal circumstances, we recommend consideration of greater integration of telegenetics into regular clinical genetic care, to supplement existing care modalities. Professional cooperation, sharing knowledge, and establishing guidelines on a national and international level could contribute to successful and more widespread implementation of telegenetics. However, the perceived practical and regulatory barriers have to be overcome.

European Journal of Human Genetics (2016) 24, 157-163; doi:10.1038/ejhg.2015.83; published online 22 April 2015

\section{INTRODUCTION}

Clinical genetic services are currently facing major challenges: budget limitations, increasing patient numbers, and more tests to communicate, result in ever greater pressure on time. Moreover, patient centeredness is playing an increasingly prominent role. The recent introduction of next-generation sequencing (NGS) techniques illustrates the challenges: NGS has great potential for diagnosing many more syndromic/heritable diseases than with conventional techniques, resulting in more patients being referred for genetic counseling and testing. Moreover, our limited or incomplete ability to interpret NGS results necessitates follow-up contacts. More efficient ways of genetic counseling that maintain high standards of care and facilitate shared decision making are therefore needed. Telemedicine could, in our view, be a mode to achieve this in a substantial part of referrals to clinical genetic centers.

Telemedicine is defined as remote health care to exchange medical information from one site to another via electronic communications to improve a patient's health (http://www.americantelemed.org/abouttelemedicine/what-is-telemedicine). It can be used both in communication between professionals and patients, and in communication between professionals about patients. Telemedicine modalities range from telephone consultation as the earliest or simplest form, to communication via a computer and webcam, to using a specialized portable workstation with attached devices to visualize and measure body parts and functions. A common goal of telemedicine applications throughout various medical disciplines is to provide an effective, efficient, and patient-friendly way of care. ${ }^{1-3}$ Moreover, it can reach patients who are difficult to reach by conventional 'in-person' care methods, for example, due to large distances and traveling costs. ${ }^{4,5}$

Telemedicine has been introduced in various medical disciplines, including clinical genetics, where it has been referred to as telegenetics. The small number of existing reports on telegenetics in oncogenetics and prenatal and dysmorphologic consultations are mainly from outside Europe. Although there are a few UK reports, ${ }^{6-8}$ the overall application in Europe is unknown. Reported patient experiences are very positive overall, while those of professionals are moderately positive, influenced to a large extent by technical imperfections. ${ }^{6-11}$ No formal international guidelines exist for when and how to use telegenetics in a responsible way. There are also no widespread European or worldwide collaborations on telegenetics, for exchange of knowledge to allow for quality improvement and responsible application of telegenetic modalities. In the United States, there is a national Telegenetics Workgroup to facilitate cooperation and exchange between various regional telegenetics initiatives.

It is conceivable that various local initiatives in Europe do exist, however, and face similar problems, barriers, and challenges, with local professionals trying to solve these by themselves. Given the generally experienced barriers on telemedicine on the one hand, and positive literature reports on telegenetics use on the other, we wanted to get an impression of the extent and types of telegenetics use throughout Europe and the barriers that are faced, and to aim for collaboration between different centers, as appropriate. To address this, we conducted an international survey among European Society of

\footnotetext{
${ }^{1}$ Department of Genetics, University Medical Center Groningen, University of Groningen, Groningen, The Netherlands; ${ }^{2}$ Wessex Clinical Genetic Service, Southampton, UK; ${ }^{3}$ Faculty of Medicine, Clinical Ethics and Law Unit, University of Southampton, Southampton, UK; ${ }^{4}$ Department of Health Psychology, University Medical Center Groningen, University of Groningen, Groningen, The Netherlands

${ }^{*}$ Correspondence: E Otten or Professor IM van Langen, Department of Genetics, University Medical Center Groningen, Hanzeplein 1, PO Box 30001,9700 RB Groningen, The Netherlands. Tel: +31 50361 7229; Fax: +31 50361 7231; E-mail: e.otten@umcg.nl or i.m.van.langen@umcg.nl Received 6 February 2015; revised 25 March 2015; accepted 27 March 2015; published online 22 April 2015
} 
Human Genetics (ESHG) members to serve as a baseline upon which to superimpose improvements in telegenetics provision.

\section{MATERIALS AND METHODS}

\section{Survey design}

We composed an online survey in collaboration with the American Telegenetics Workgroup of the National Coordinating Center for the Regional Genetic and Newborn Screening Service Collaboratives (NCC). Our survey questions covered four outcome measures: (1) respondents' professional characteristics, (2) the availability and use of various telegenetics applications by the respondents, (3) reasons for non-availability or non-usage of videoconferencing applications at the respondents' departments, and (4) respondents' interests in telegenetics initiatives and/or collaboration. Design and dissemination of the survey were performed using the online software tool SurveyMonkey (www.surveymonkey.com; Palo Alto, CA, USA).

\section{Survey distribution}

All 929 members of the ESHG for whom the e-mail addresses were available for public use were invited to participate in the online survey between November 2012 and January 2013. The list of e-mail addresses was provided by the ESHG committee and contained no information about the members' professional backgrounds (eg, clinically active or not, working in health care or business). Within the time period, one reminder e-mail was sent to all available members.

\section{Analysis}

We excluded respondents from outside Europe and those who were not working in a clinical setting. Data were analyzed using SPSS statistics v22 (IBM Corporation, Armonk, NY, USA). As descriptive statistics we used mean (SD) and median/range, and $n$ (\%) for nominal and ordinal variables. We analyzed the outcomes on telemedicine availability and use for the whole group, and for different respondent groups based on the European region in which they were employed.

\section{RESULTS}

\section{Respondents' characteristics}

The survey was fully or partially completed by 121 ESHG members from 92 different institutions in 39 countries, comprising 108 European respondents from 30 different countries (Table 1). We excluded the 13 non-European respondents (of whom one was not working in a clinical setting) and four European respondents who were not working in a clinical setting. This left 104 clinically working European respondents for further analysis. Of these, $65 \%$ were clinical geneticist, $16 \%$ genetic counselors, $12 \%$ laboratory specialists, and $7 \%$ had other clinical specialties (Figure 1). Of these 104 respondents, $86 \%$ indicated they worked at a public hospital, while $14 \%$ worked in a private clinic. Their working experience ranged from 0 to 40 years (mean 18.6 years).

\section{Availability and use of telegenetics applications}

Of all the European respondents, 28\% ( $n=29$; of which 17 clinical geneticists, 6 genetic counselors, 4 lab specialists, and 2 'other') indicated that they used at least one subtype of telegenetics. Most users were from northern Europe $(41 \% ; n=12)$ and the smallest proportion was from eastern Europe $(6.9 \% ; n=2)$. Telephone-only genetic counseling was the telemedicine subtype used by the largest number of respondents; $17 \%$ of respondents $(n=18)$. Figure 2 shows the geographical location of users. The extent of use varied among respondents from 1 to 25 counseling sessions to over 100 counseling sessions per year, for various indications. Few respondents used videoconferencing, and then most frequently through a telemedicine dedicated facility at their department. This modality was used by $9.6 \%$ $(n=10)$ of all respondents (Figure 2) mostly from western European countries (7 of 10 respondents). The frequency of use ranged from
Table 1 Residence of respondents listed by region, country, and location

\begin{tabular}{|c|c|c|}
\hline Residence & Number of respondents & Number of locations \\
\hline \multicolumn{3}{|c|}{ European respondents $(n=108)$} \\
\hline \multicolumn{3}{|c|}{ Western Europe $(n=36)$} \\
\hline Austria & 5 & 2 (+1 unknown) \\
\hline Belgium & 1 & 1 \\
\hline France & 7 & 6 \\
\hline Germany & 6 & 5 (+ 1 unknown) \\
\hline Netherlands & 15 & 7 \\
\hline Switzerland & 2 & 2 \\
\hline \multicolumn{3}{|c|}{ Eastern Europe $(n=15)$} \\
\hline Bulgaria & 2 & 2 \\
\hline Estonia & 2 & 2 \\
\hline Latvia & 1 & 1 \\
\hline Lithuania & 1 & 1 \\
\hline Poland & 1 & 1 \\
\hline Romania $^{a}$ & 7 & 4 \\
\hline Ukraine & 1 & 1 \\
\hline \multicolumn{3}{|c|}{ Northern Europe $(n=25)$} \\
\hline Denmark $^{\mathrm{a}}$ & 4 & 4 \\
\hline Finland & 2 & 1 \\
\hline Iceland & 2 & 1 \\
\hline Ireland & 2 & 2 \\
\hline Norway & 1 & 1 \\
\hline Sweden & 5 & 3 \\
\hline United Kingdom & 9 & 7 \\
\hline \multicolumn{3}{|c|}{ Southern Europe $(n=32)$} \\
\hline Croatia & 1 & 1 \\
\hline Cyprus & 1 & 1 \\
\hline Greece & 2 & 2 \\
\hline Italya & 9 & 8 \\
\hline Macedonia & 1 & 1 \\
\hline Malta & 1 & 1 \\
\hline Portugal & 2 & 2 \\
\hline Slovenia & 1 & 1 \\
\hline Spain $^{\mathrm{a}}$ & 10 & 7 (+1 unknown) \\
\hline Turkey & 4 & 2 \\
\hline \multicolumn{3}{|c|}{ Non-European respondents $(n=13)$} \\
\hline \multicolumn{3}{|c|}{ Africa $(n=1)$} \\
\hline Angolaa & 1 & 1 \\
\hline \multicolumn{3}{|l|}{ Oceania $(n=2)$} \\
\hline Australia & 2 & 2 \\
\hline \multicolumn{3}{|l|}{ Middle-East $(n=5)$} \\
\hline Bahrain & 1 & 1 \\
\hline Iran & 2 & 1 \\
\hline Kuwait & 1 & 1 \\
\hline Saudi Arabia & 1 & 1 \\
\hline \multicolumn{3}{|c|}{ South-America $(n=1)$} \\
\hline Brazil & 1 & 1 \\
\hline \multicolumn{3}{|l|}{ North-America $(n=4)$} \\
\hline Canada & 1 & 1 \\
\hline USA & 3 & 3 \\
\hline
\end{tabular}

${ }^{a}$ One respondent from each of these five countries was excluded from further analyses because of being not working in clinical practice.

1-25 to 26-50 counseling sessions per respondent per year, for a range of different indications. For each telemedicine modality, we analyzed the relative frequencies of the different types of clinical interactions for which it was used (Figure 3). Figure 3 shows that the telephone is most frequently used for genetic counseling, the office workstation and 


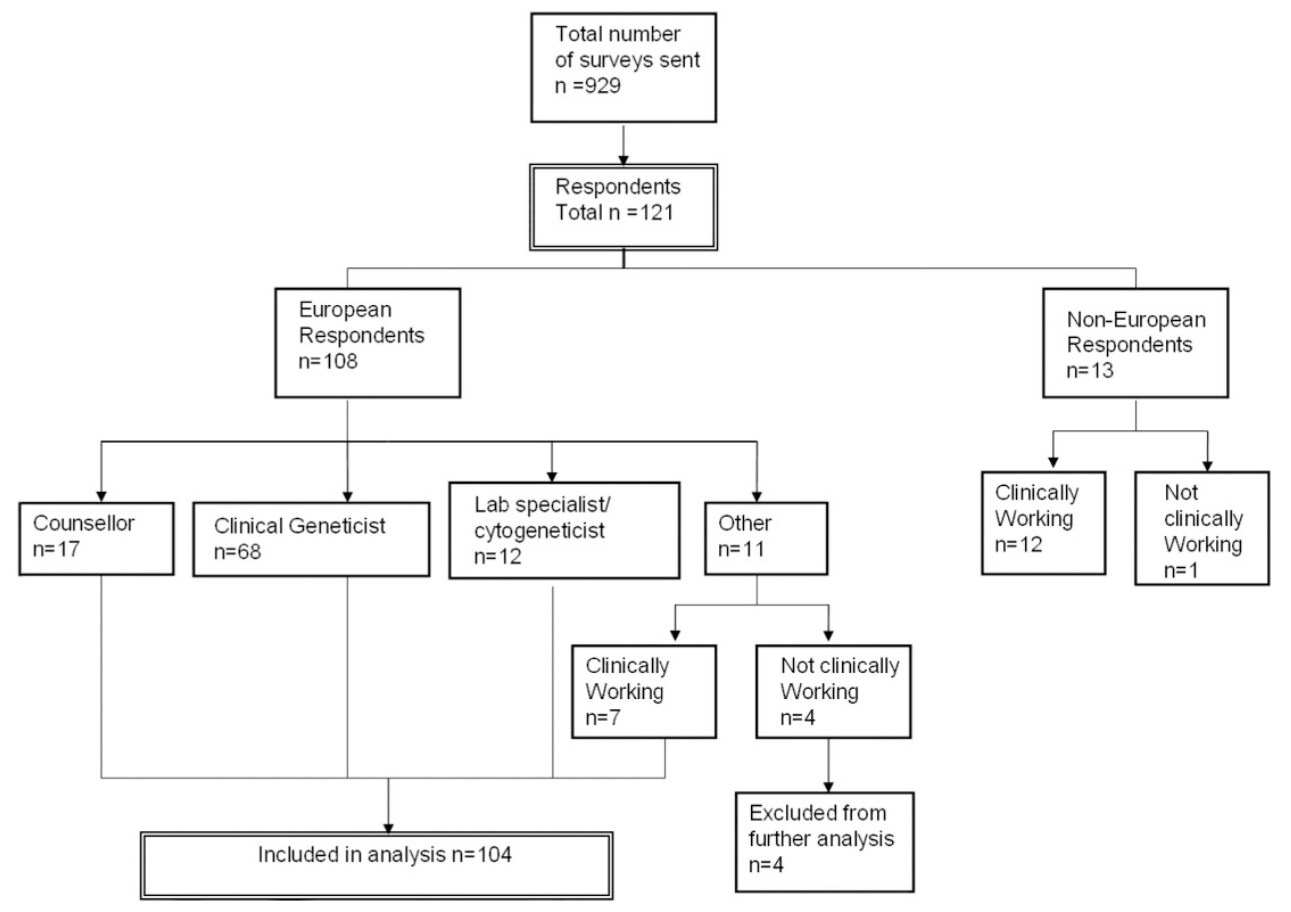

Figure 1 Overview of approached and responded ESHG members.

dedicated facility are mostly used for 'outpatient evaluation and management' and 'inpatient evaluation and management' (including, for example, assessing children with mental retardation/multiple congenital anomalies, when admitted to the hospital, or visiting the outpatient department, respectively).

\section{Availability and use of videoconferencing facilities}

We investigated which part of respondents had videoconferencing facilities available for performance of patient consultations: $25 \%$ ( $n=24$ of 97, of whom 17 clinical geneticists and 4 genetic counselors) had such facilities available for use. These respondents originated from a wide range of countries $(n=12)$, most of them $(n=13 ; 54 \%)$ from western Europe. The most frequently indicated reasons for videoconferencing facilities not being available in respondents' departments were lack of money $(n=28 ; 38.4 \%)$, lack of reimbursement $(n=26$; $35.6 \%$ ), lack of interest by counselors $(n=23 ; 31.5 \%)$, and lack of need because of small geographical distances $(n=23 ; 28.8 \%)$, but a wide range of other reasons were also mentioned (Figure 4a).

Where videoconferencing facilities were available, we analyzed the extent to which these facilities were actually used, and the reasons for non-usage. Only $8 \%$ ( 2 of 24 ) of these respondents actually made use of videoconferencing facilities in direct patient care (genetic counseling) rather than in supportive patient care (eg, multidisciplinary consultation or expert consultation; 10 of 24 (41.7\% respondents)). The reasons given for not using the available facilities in direct patient care were mostly lack of need because of small distances $(n=10$; $45.5 \%$ ), and not having a patient population suitable for video conferencing ( $n=6 ; 27.3 \%)$ (Figure $4 \mathrm{~b})$.

\section{Interest in telegenetics initiatives}

Respondents were asked whether they would like to participate in a working group or attend a meeting on Telegenetics and $55 \%$ of respondents indicated their interest.

\section{DISCUSSION}

Our results suggest that clinical genetic services currently have limited availability and use of telemedicine, but also that many of our respondents are interested in learning more about it. Perhaps not surprisingly because of its well-established position in everyday life, the telephone is the most-used modality in direct patient care, used by $17 \%$ of respondents, mainly for genetic counseling. Videoconferencing facilities were used by a much smaller proportion, mostly in supportive professional activities and only rarely in direct patient care. Northern and western European respondents had greater availability and therefore more use of telegenetics modalities than those from eastern and southern Europe, although the numbers are too small to draw firm conclusions.

We were unable to determine the response rate of clinically active genetic professionals among the members who received our survey because the professional backgrounds of the non-responders were not known. It is possible our results were biased toward genetics professionals who are interested in telegenetics as they might be more likely to respond. This could mean that professionals' uptake rates of telegenetics are even lower than our survey suggests, but also that the telegenetics uptake rates at the institutional level are actually higher. However, we believe our survey does give a valuable snapshot of current practice in many European countries and clinical genetic institutions, from which we can conclude that there is room for expansion.

Besides providing value in direct patient care, telegenetics is also seen as a valuable tool in supportive patient care, both being in use by our respondents. Given the expanding discussion about 'mainstreaming' genetics, we believe that telegenetics could be a useful modality and improve genetics engagement by other medical specialisms. It can provide accessible and widely available contact options for multidisciplinary and peer consultation, as well as pre- and post-test online genetic counseling for patients from other medical specialists or general practitioners by trained genetic professionals. Finally, 
a Use of Telemedicine modalities among European respondents

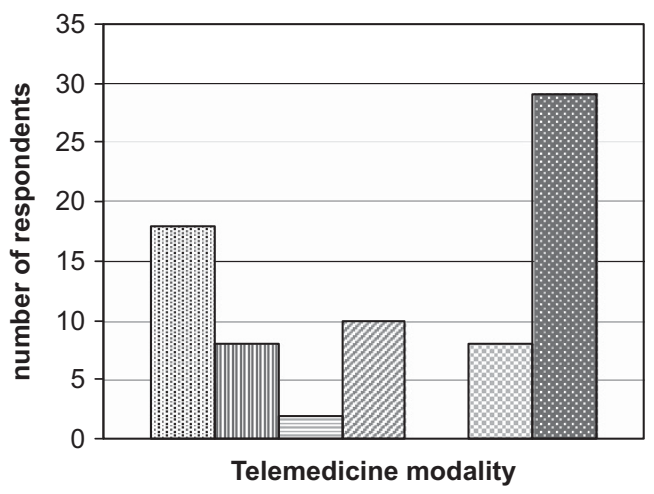

田 telephone-only full genetic counseling

ए video conferencing using office workstation (PC + webcam)

$\boxminus$ video conferencing using mobile devices (smart phone, tablet, laptop)

$\square$ video conferencing using dedicated facility (unit in videoconferencing room)

$\square$ video conferencing using specialized portable workstation (mobile cart with attached devices)

$\square$ other

at least one of the modalities

b

Use of Telemedicine modalities among western European respondents

C Use of Telemedicine modalities
among northern European respondents

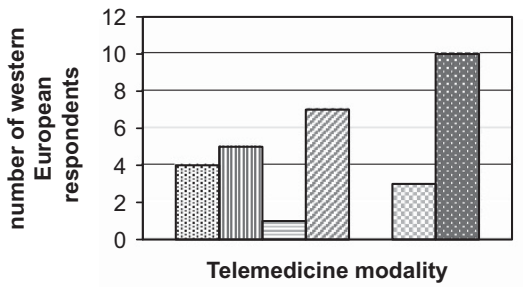

d

Use of Telemedicine modalities among eastern European respondents

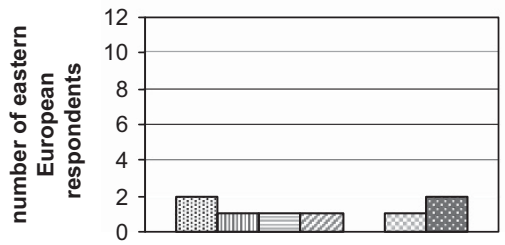

Telemedicine modality

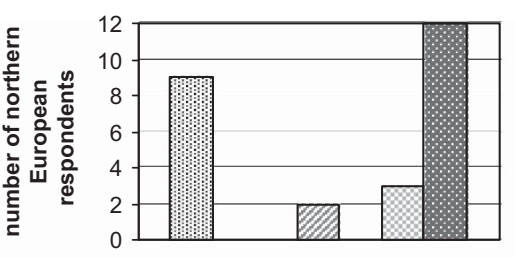

Telemedicine modality

Use of Telemedicine modalities among southern European respondents

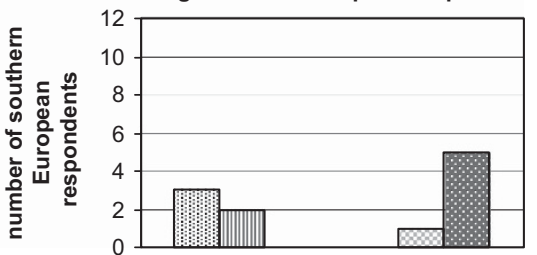

Telemedicine modality

Figure 2 Telemedicine modalities in use by European respondents ( $n=29$ respondents).

Telemedicine modalities: individual roles in online patient communication for various clinical interactions
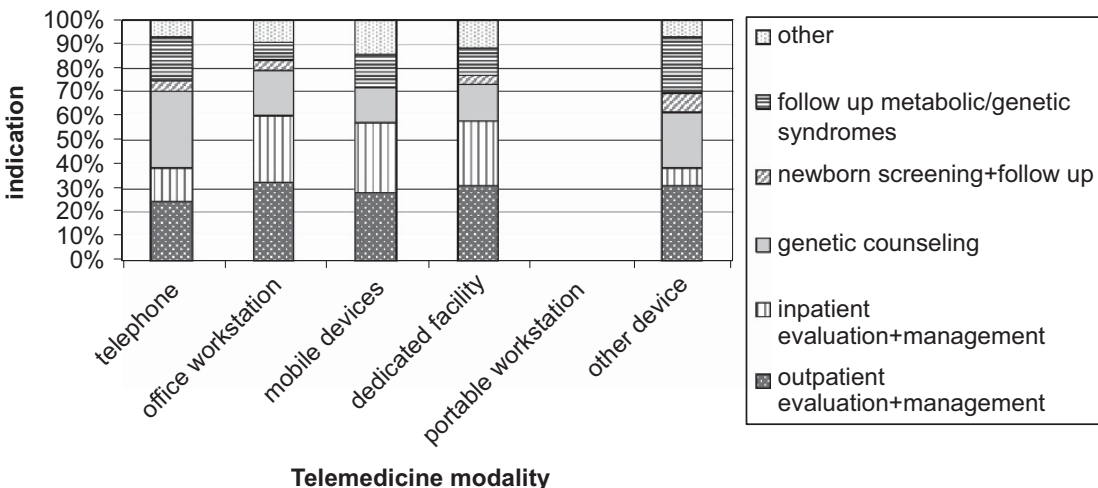

目 follow up metabolic/genetic syndromes

믄 newborn screening+follow up

$\square$ genetic counseling

m inpatient

evaluation+management

outpatient

evaluation+management

Telemedicine modality

Figure 3 Overview of telemedicine modalities in use by European respondents, showing their individual roles in online patient communication for various indications. 


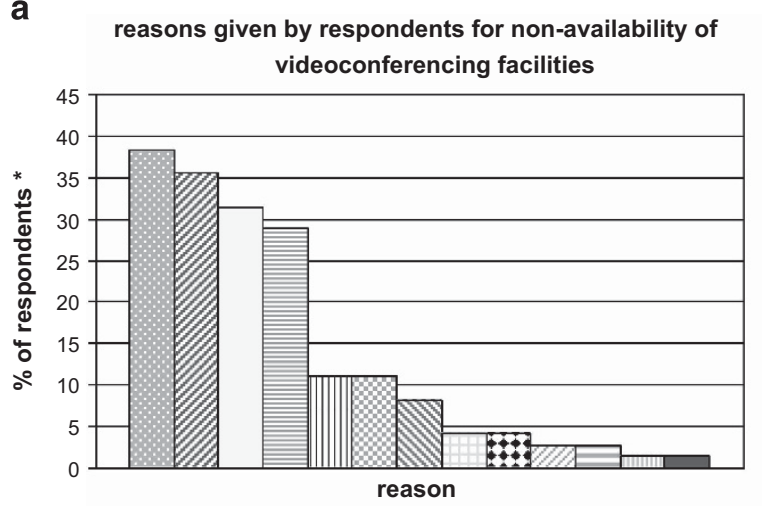

b

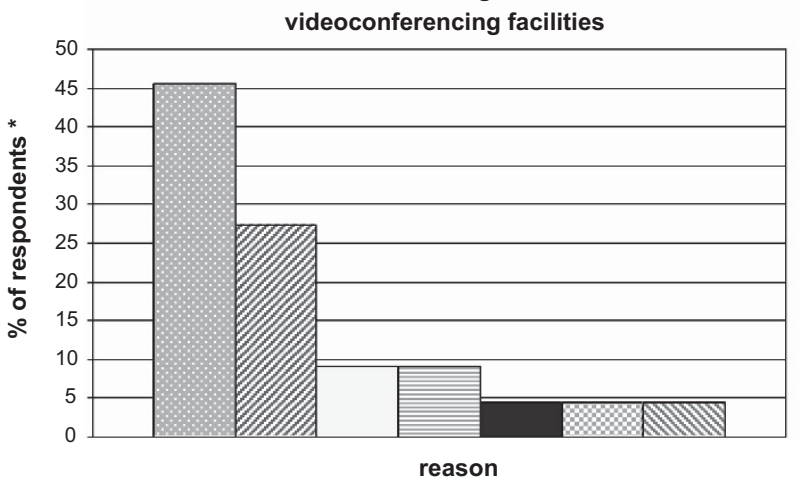

$\square$ no money available

$\checkmark$ no reimbursement

$\square$ no interest from employees

$\exists$ small geographical distances

$\square$ shortage of technique/internet

$\square$ no need/interest

Q unknown reasons

$\square$ concerns about confidentiality

$\checkmark$ quality concerns

$\square$ shortage of time

口 lack of facilities

$\square$ unawareness of possibilities

complexity of organizing

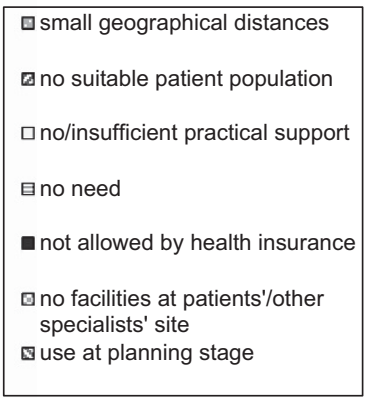

Figure 4 (a) Reasons for non-availability of videoconferencing facilities. $* \%$ represents the proportion of respondents who stated each reason relative to the total number of respondents without availability of videoconferencing facilities $(n=73)$. Respondents could indicate more than one reason. (b) Reasons for non-usage of available videoconferencing facilities. $* \%$ represents the proportion of respondents who stated each reason relative to the total number of respondents who had videoconferencing facilities available but did not use them in direct patient care $(n=22)$. Respondents could indicate more than one reason.

telegenetics could have an important role in recontacting former patients in light of new information from previous diagnostic testing. Using telegenetics to connect laboratories, counselors, patients, and other health-care professionals could facilitate more routine recontacting than currently takes place. ${ }^{12,13}$

We concluded three main points from our survey: First, the current availability and use of telegenetics is limited and could be extended, even without the purchase of new equipment, since there were discrepancies between availability and use. Second, as Figure 3 illustrates each different telegenetic modality is used for many types of activities even though respondents might have listed preferential use in particular situations. And third, cooperation, education, and finally practical guidelines might be helpful for successful telegenetics application. More widespread use of telemedicine in genetics might be presumed right now, but this seems not to be so. This snapshot of the current state of play and of the barriers professionals experience could be useful in planning future implementation.

Respondents indicated various barriers to greater current use, that could be divided into (1) lack of perceived suitability and need, (2) practical constraints (eg, lack of resources and supportive regulations), and (3) lack of professional support/knowledge. Because both the availability and use of videoconferencing by our respondents were still limited, and consequently most respondents lack experiences with telegenetics, it could be that the barriers they reported were perceived rather than real. This could, for example, be the case for the argument of having no suitable patient population: contrary to the perceptions of respondents, telemedicine is, in our experience, particularly suited to clinical genetics because for many patients, especially in oncogenetics, cardiogenetics, and neurogenetics, the consultation consists largely of communication, rather than requiring technical aids or physical examination. However, online genetic consultation does not preclude examination-dysmorphologic evaluation, among other genetic applications, has been reported as successful. ${ }^{14-17}$

Another reason mentioned by respondents for not using telemedicine facilities is because they did not perceive a need. This could reflect current adequate coverage of their own referral patch by in-person care, or indeed that there is a perception that in-person counseling is the gold standard, and telemedicine should only be applied when inperson counseling is not possible. This aspect needs further exploration. We consider telegenetics holds potential in terms of improving patient access to health professionals and adapting to their wishes or preferences: It allows patients for example to receive genetic care in their own home at a time convenient to them, thereby avoiding traveling time and costs. ${ }^{4,18}$ Moreover, telegenetics could allow for increased flexibility and efficiency for counselors too. Previous research has shown that perceptions and evaluations of telegenetics vary between patients and professionals: patients mainly judge telegenetics initiatives as very positive, while professionals are generally positive, but are also aware of communication and technical restrictions. ${ }^{6,7,9,11}$

We do not envisage or recommend that telegenetics replaces inperson consultations completely, but it will be important to assess in 
which situations both patients and professionals might use it as a good alternative or supplement to regular care. While we discussed all telegenetics modalities collectively, in some instances videoconferencing might be preferable to telephone counseling, because it allows for the use of different visual aids and assessment of, at least some, nonverbal communication, which is often considered very valuable in genetic consultation. ${ }^{19,20}$ However, telephone counseling has a clearly established role and seems to be effective in satisfying some patient needs, ${ }^{21,22}$ and moreover, can be used effectively in conjunction with in-person consultations. It is likely that different situational requirements will require different modalities. For example, certain videoconferencing modalities might be used preferentially to others; videoconferencing-only for a straightforward follow-up discussion, but specialized workstation with attached devices for detailed evaluation and physical examination. Wider discussion on the relative merits of different modalities could help clinically active professionals to plan which telemedicine modality to use and when.

Existing practical barriers, for example, lack of available facilities, money, manpower, and knowledge, are important aspects to address, when considering setting up or expanding telegenetics initiatives. The ways to overcome these barriers will differ in different settings/ countries, and influenced for example by geographical distance, economic resources at the professionals' and patients' disposal, the number and distribution of available professionals, and national regulations concerning e-health initiatives. Some obstacles might be overcome by cooperation and exchange of experiences/ knowledge between professionals. The introduction of electronic health records in many hospitals in the near future, and parallel developments in the field of hospital-ICT are likely to contribute to increased telegenetics facilitation. Moreover, the use of e-health applications in recent years is being facilitated by several European governments, research funding agencies, and health insurance companies. It will be important to ensure that privacy aspects are well covered in any of these developments. Improving the quality of telegenetics applications, and adapting to data protection requirements of hospitals and health systems will be important. According to the American Telemedicine Association core operational guidelines, a connection should for example at least be encrypted to ensure a secure exchange of sensitive patient information (http://www.americantelemed.org/docs/default-source/standards/coreoperational-guidelines-for-telehealth-services.pdf?sfvrsn =6). Practical experiences by both patients and professionals will clarify and further solve the privacy issues encountered in telegenetics.

A substantial proportion of our respondents were interested to improve their knowledge on telegenetics, suggesting that they are considering or willing to integrate this other way of working in their practice, but need help in achieving it. The importance of gaining more widespread knowledge on telegenetics, and of increasing its prominence and integration with other regular care modalities is underlined by various examples, like positive patient evaluations of telegenetics, developments in present-day society ensuring that more and more people gain access to online resources, the scarcity of genetics professionals in many countries, and the changing context/ dynamics within clinical genetics.

To make telegenetics successful genetics professionals will need to be convinced that it can at least be considered equivalent to in-person consultation in some settings and thus part of 'good care', besides being adequately supported in different ways. Only then they will be inclined to implement it in daily practice. ${ }^{23-25}$

We consider that the time has come to integrate telegenetics into patient care more routinely, thereby maintaining quality of care and effectiveness, increasing efficiency, and respecting the importance of patient centeredness. This survey, as well as the educational satellite meetings on telegenetics we organized during the 2013 and 2014 ESHG conferences in Paris and Milan respectively, are the first steps we took in this respect. We have set up an online telegenetics discussion group on the platform LinkedIn, which currently has 20 members from in and outside Europe (requests for membership to corresponding author). Moreover, it would be valuable to involve both professionals and patients in establishing and expanding telegenetics initiatives and in establishing practical guidelines. In the United States, these have been developed for various medical disciplines by the American Telemedicine Association (http://www.americantelemed.org/resources/standards/atastandards-guidelines), but in Europe this relevant information has, to the best of our knowledge, not been compiled yet.

To conclude, telegenetics use in Europe seems to be limited in clinical genetics practice so far, with several practical, and possibly also psychological, barriers contributing to this. In our opinion, expanding the use of telegenetics is needed in the light of current developments in genetics and today's society, and there is interest in expansion and sharing of knowledge about telegenetics between genetics professionals at an international level. Establishing a European Working Group on telegenetics and developing guidelines could be the next steps for creating optimal conditions for a wider application of telegenetics facilities and for improving its quality.

\section{CONFLICT OF INTEREST}

The authors declare no conflict of interest.

\section{ACKNOWLEDGEMENTS}

We thank Jerome del Picchia and Karin Knob from the European Society of Human Genetics, for providing e-mail addresses of ESHG members that were available for external use. We are also grateful to Silvia Mann and the other members of the NCC Telegenetics workgroup for giving us insight into their survey design, to Jackie Senior and Kate McIntyre for editing our manuscript, and to all the respondents for their participation.

1 Wade VA, Karnon J, Elshaug AG, Hiller JE: A systematic review of economic analyses of telehealth services using real time video communication. BMC Health Serv Res 2010; 10: 233.

2 Dellifraine JL, Dansky KH: Home-based telehealth: a review and meta analysis. J Telemed Telecare 2008; 14: 62-66.

3 Myers KM, Valentine JM, Melzer SM: Child and adolescent telepsychiatry: utilization and satisfaction. Telemed J E Health 2008; 14: 131-137.

4 Mehrota A, Paone S, Martich GD, Albert SM, Shevchik GJ: Characteristics of patients who seek care via evisits instead of office visits. Telemed J E Health 2013; 19: 1-5.

5 Merell RC: Editorial:Telemedicine for vulnerable populations. Telemed J E Health 2014; 20: 885-886.

6 Gray J, Brain K, Iredale R, Alderman J, France E, Hughes H: A pilot study of Telegenetics. J Telemed Telecare 2001; 7(suppl 2): 68-70.

7 Iredale R, Gray J, Murtagh G: Telegenetics: a pilot study of video-mediated genetic consultations in Wales. Int J Med Market 2002; 2: 130-135.

8 Coelho JJ, Arnold A, Nayler J, Tischkowitz M, MacKay J: An assessment of the efficacy of cancer genetic counselling using real-time videoconferencing technology (telemedicine) compared to face-to-face consultations. Eur J Cancer 2005; 41: 2257-2261.

9 d'Agincourt-Canning L, McGillivray B, Panabaker $\mathrm{K}$ et al: Evaluation of genetic counseling for hereditary cancer by videoconference in British Columbia. BC Med J 2008; 50: 554-559.

10 Zilliacus E, Meiser B, Lobb E, Dudding TE, Barlow-Stewart K, Tucker K: The virtual consultation: practitionars' experiences of genetic counseling by videoconferencing in Australia. Telemed J E Health 2010; 16: 350-357.

11 Hilgart JS, Hayward JA, Coles B, Iredale R: Telegenetics: a systematic review of telemedicine in genetics services. Genet Med 2012; 14: 765-776.

12 Aronson SJ, Clark EH, Varugheese M, Baxter S, Babb LJ, Rehm HL: Communicating new knowledge on previously reported genetic variants. Genet Med 2012; 14: 713-719.

13 Hunt K: Individualizing the Informed Consent Process for Whole Genome Squencing: A Patient Directed Approach [Dissertation]. Arizona: Arizona State University. 2013.

14 Hopper B, Buckman M, Edwards M: Evaluation of satisfaction of parents with the use of videoconferencing for a pediatric genetic consultation. Twin Res Human Genet 2011; 14: 343-346. 
15 Elliott AM, Mhanni AA, Marles SL et al: Trends in Telehealth versus on-site clinical genetics appointments in Manitoba: a comparative study. J Genet Couns 2012; 21: 337-344.

16 Lea DH, Johnson JL, Ellingwood S, Allan W, Patel A, Smith R: Telegenetics in Maine: successful clinical and educational service delivery model developed from a 3-year pilot project. Genet Med 2005; 7: 21-27.

17 Stalker HJ, Wilson R, McCune H, Gonzalez J, Moffett M, Zori RT: Telegenetic medicine: improved access to services in an underserved area. J Telemed Telecare 2006; 12 : 182-185.

18 Gardner MR, Jenkins SM, O'Neil DA, Wood DL, Spurrier BR, Pruthi S: Perceptions of video-based appointments from the patient's home: a patient survey. Telemed J E Health 2014; 21: 281-285.

19 Bradbury AR, Patrick-Miller L, Fetzer D et al: Genetic counselor opinions of, and experiences with telephone communication of BRCA1/2 test results. Clin Genet 2011, 79: $125-131$.
20 Madlensky L: Is it time to embrace telephone genetic counseling in the oncology setting? J Clin Oncol 2014; 32: 611-612.

21 Platten U, Rantala J, Lindblom A, Brandberg Y, Lindgren G: The use of telephone in genetic counseling versus in-person counseling: a randomized study on counselees' outcome. Fam Cancer 2012; 11: 371-379.

22 Sutphen R, Davila B, Shappell $\mathrm{H}$ et al: Real world experience with cancer genetic counseling via telephone. Fam Cancer 2010; 9: 681-689.

23 Whitten P, Love B: Patient and provider satisfaction with the use of telemedicine: overview and rationale for cautious enthusiasm. J Postgrad Med 2005; 51: 294-300.

24 Grigsby B, Brega AAG, Bennett RE et al: The slow pace of interactive video Telemedicine adoption: the perspective of Telemedicine program administrators on physician participation. Telemed J E Health 2007; 3: 645-656.

25 Barton PL, Brega AG, Devore PA et al: Specialist physicians' knowledge and beliefs about Telemedicine: a comparison of users and nonusers of the technology. Telemed J E Health 2007; 13: 487-499. 